\title{
MODERNA ARHITEKTURA: PROBLEMATIKA VARSTVA IN ZAŠČITE
}

Ključne besede: moderna arhitektura, Ljubljanska arhitekturna šola, arhitekturna dediščina, ohranjanje moderne arhitekture, pravno varstvo dediščine

Nekateri objekti slovenske moderne arhitekture, zgrajeni v obdobju med letom 1945 in uveljavitvijo postmodernizma ob koncu sedemdesetih let preteklega stoletja, pomenijo poseben ali celo prelomen dosežek arhitekturnega ustvarjanja pri nas. Arhitekti Ljubljanske arhitekturne šole, $\mathrm{z}$ Edvardom Ravnikarjem na čelu, so s svojim delovanjem zaznamovali vrh slovenske moderne arhitekture $\mathrm{v}$ šestdesetih letih preteklega stoletja. Kljub temu, da od zgraditve večine njihovih arhitektur ni minilo več kot petdeset let, so te ponekod slabše ohranjene kot na primer secesijske ali baročne stavbe. Zaradi prezidav so nekateri objekti skoraj neprepoznavni, ob nezadostni zaščiti pa je prišlo celo do neupravičenih rušilnih posegov. Tako se postavljata naslednji vprašanji: kako je urejena zaščita spomenikov moderne arhitekture v Republiki Sloveniji in kakšna je značilna konservatorska problematika ob ohranjanju tega stavbnega fonda?

\section{Moderna arhitektura v svetovnem okviru}

Izraz moderna arhitektura zaznamuje stavbe dvajsetega stoletja, ki kažejo nove oblikovne, konstrukcijske in tudi socialne težnje. Za arhitekturo tega obdobja je bilo značilno odrekanje zgodovinskemu in nacionalnemu izročilu, umirjena in stroga arhitekturna govorica, prizadevanje, da bi izlo- 
čili vse odvečne elemente, ter poudarjeno zanimanje za funkcionalno ureditev. Razvoj industrijske tehnike in materiali, kot so beton, jeklo, železo, železobeton in steklo, so omogočili nastanek novih gradbenih tehnik in s tem odprli nove možnosti načrtovanja. Uveljavila se je skeletna gradnja, ob njej pa industrijsko izdelani stavbni elementi, ki so vodili do nastanka nekoč nepredstavljivih arhitektur.

Po prvi svetovni vojni so se te arhitekturne novosti v svetu že povsem uveljavile in privedle do nadvlade »modernega sloga«. Ključni nosilci tega arhitekturnega razvoja so bili arhitekti Walter Gropious, Ludwig Mies van der Rohe in Charles Eduard Jennearet, im. Le Corbusier, ki je s svojimi "petimi točkami« zajel osnovna načela arhitekture modernega gibanja. Kot temeljno vodilo svojega ustvarjanja je namreč leta 1926 objavil t. i. pet točk. Stavba naj bi bila zgrajena na sistemu pilotov, masa stavbnega volumna pa naj bi bila dvignjena nad zemljo. Tradicionalno kritje s strešinami naj bi nadomestila ravna streha. Na njej naj bi bil zasnovan vrt. Tloris naj bi bil svoboden, nosilne stene naj bi namreč nadomestili vitki stebri. Fasado naj bi oblikovali pretežno gladki beli zidovi in značilna horizontalna okna. Poenotenje teh revolucionarnih arhitekturnih načel na svetovni ravni je vodilo do internacionalizacije modernega gibanja ter do t. i. mednarodnega sloga (Umetnost: svetovna zgodovina, 2000, 613).

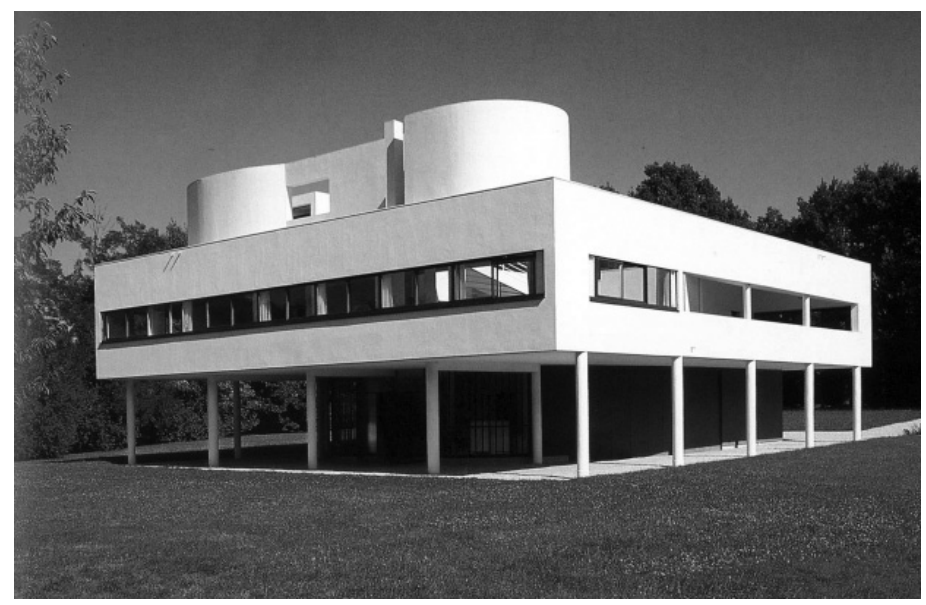

slika 1: Le Corbusier, Villa Savoye, dokončana leta 1929 Jasno se kaže upoštevanje načela "petih točk «. Vir: http://en.wikipedia.org/wiki/Le_Corbusier 


\section{Liubljanska arhitekturna šola kot sinonim za slovensko moderno arhitekturo}

V Sloveniji je ob nastopu dvajsetega stoletja arhitekturno ustvarjanje obvladoval historizem, ob njem pa se je v Ljubljani uveljavljala zlasti secesija. Bistveno vlogo so tedaj odigrali predvsem slogovno samosvoji Maks Fabiani, Jože Plečnik ter kasneje Ivan Vurnik. V obdobju po prvi svetovni vojni pa so se tudi pri nas postopoma začele uveljavljati modernistične težnje. Modernistično arhitekturno delovanje se je na Slovenskem naslonilo na različna teoretična in praktična izhodišča, največkrat pa je imenovano kar funkcionalizem (Zupan, 2001, 6). Funkcionalizem je prevladoval konec dvajsetih in $\mathrm{v}$ tridesetih letih preteklega stoletja, arhitekturno ustvarjanje pa je bilo osredotočeno v Ljubljani (Bernik, 1998, 301). Na ljubljanski univerzi je bil leta 1919 ustanovljen tudi Oddelek za arhitekturo. V okviru oddelka sta v naslednjih letih poglavitna seminarja prevzela Ivan Vurnik, njegov glavni pobudnik, ter Jože Plečnik. Skupaj in v medsebojnem tekmovanju sta postavila temelje Ljubljanske arhitekturne šole (Dolenc Šoba, 2007, 268).

Po drugi svetovni vojni so ideje, ki so se oblikovale do začetka vojne, predstavljale izhodišče razvoja slovenske arhitekture v drugi polovici stoletja. Leta takoj po vojni so zaznamovala dela arhitektov, ki so kazali kontinuiteto funkcionalističnih teženj. ${ }^{1} \mathrm{~V}$ sredini petdesetih let pa se je slovenski arhitekturni prostor začel odpirati proti novim svetovnim pobudam. Dovzetnost zanje je vodila v oblikovni pluralizem, ki je dopuščal širok spekter možnosti reševanja urbanističnih in arhitekturnih nalog. V šestdesetih letih se je arhitekturna raznovrstnost še stopnjevala. Arhitekti so namreč presegli stroge okvire oblikovanja in so ustvarjali v različnih slogovnih variantah in sintezah (Bernik, 1992, 41). V tem desetletju je bistveno vlogo odigrala Ljubljanska arhitekturna šola, katere vodilna osebnost je bil najvidnejši slovenski arhitekt druge polovice dvajsetega stoletja Edvard Ravnikar. Bil je najpomembnejši Plečnikov učenec. Leta 1946 je na ljubljanski Fakulteti za arhitekturo zasedel mesto profesorja (Hommage à Edvard Ravnikar: 1907-1993, 1995, 16). Poleg arhitekta Eda Mihevca je vodil seminar,

1 Ti arhitekti so bili Edvard Ravnikar, Edvard Mihevc, France Tomažič, Stanko Rohrman, Emil Navinšek, Jože Platner, Miroslav Gregorič, Danilo Fürst, Marko Župančič, Feri Novak, Oton Gaspari, Jaroslav in Milan Černigoj ter še mnogi drugi. 
pri katerem se je s študenti ukvarjal s širokim spektrom nalog. Delovanje njegovih učencev Milana Miheliča, Savina Severja, Stanka Kristla, Miloša Bonče, Otona Jugovca, Franceta Ivanška, Marka Šlajmerja, Vlada Emeršiča, Mitje Jernejca, Boruta Pečenka in drugih je bilo primerljivo s sodobnim dogajanjem v svetu. Slovensko arhitekturno ustvarjanje je tako v šestdesetih letih $\mathrm{z}$ arhitekti, ki so oblikovali Ljubljansko arhitekturno šolo, doseglo enega svojih vrhuncev (Koselj, 1995, 18).
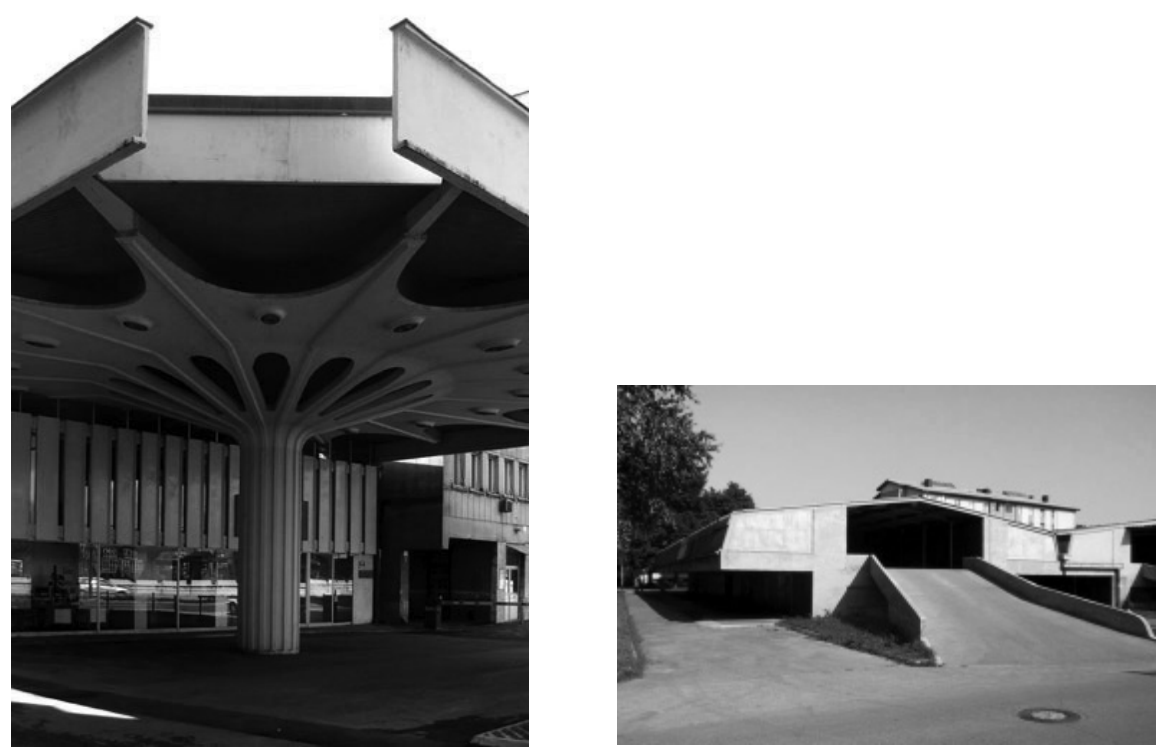

slika 2: Širok spekter arhitekturnih nalog. Milan Mihelič, gobasta nadstrešnica bencinskega servisa Petrol, Ljubljana, 1968

Vir: http://www.arhitekturni-vodnik.org/?object $=33 \& \operatorname{mode}=1 \&$ pic $=680 \& \mathrm{pl}=0 \& \mathrm{o}=0$ \& $\mathrm{a}=14$. Savin Sever, garažna hiša Triplex A in Triplex B, Ljubljana, 1966.

Vir: http://www.arhitekturni-vodnik.org/?object $=88 \&$ mode $=1 \& \mathrm{a}=55$

V sedemdesetih letih je za arhitekturno ustvarjanje po eni strani značilno nadaljevanje teženj Ljubljanske arhitekturne šole, po drugi pa njihovo zanikanje. Konec desetletja je arhitekturni razvoj zaznamoval nastop nove generacije arhitektov, t. i. generacije $a b .^{2}$ Osemdeseta leta so bila obdobje,

2 Predstavniki generacije $a b$ so bili arhitekti Vojteh Ravnikar, Janez Koželj, Aleš Vodopivec, Jurij Kobe in drugi. 
ko so ustvarjalci opustili modernistično podobo arhitekture in odprti eksperimentalni značaj arhitekturnega snovanja, saj je bil to že čas, v katerem so prevladale postmodernistične težnje. To je bil tudi čas zatona Ljubljanske arhitekturne šole (Dešman, 2001, 33).

\section{Beton - posebnost moderne arhitekture}

Stavbna dediščina obdobja moderne kaže povsem specifična arhitekturna načela. Poleg novosti v oblikovanju zunanjščin in v sami konstrukciji stavb je posebnost moderne arhitekture tudi sam gradbeni material. Kot osrednje gradivo namreč nastopa beton.

Uporabljali so ga že v starem Rimu, kjer so bili odkriti tudi ostanki armiranega betona. ${ }^{3}$ Po padcu imperija je bil t. i. rimski beton pozabljen in ponovno odkrit šele v začetku 15. stoletja. Postopoma so ga začeli uporabljati za posamezne konstrukcijske elemente, zlasti za doke, temelje, valobrane ipd. Z odkritjem Portland cementa v prvi polovici 19. stoletja pa se je začelo obdobje betona in betonskih konstrukcij v današnjem pomenu besede (Sanacije betonskih objektov, 2004, 14). V 20. stoletju je sledil velik razmah uporabe tega materiala, tehnologija betona je zlasti napredovala po drugi svetovni vojni. Pojavile so se nove vrste sestavin - cementov, agregatov in dodatkov. ${ }^{4}$ Uveljavila se je tudi prefabrikacija betonskih elementov (Mehta, Monteiro, 2006, 3).

V slovenski arhitekturi se je armirani beton dokončno uveljavil v sredini petdesetih let. Arhitekti so ga uporabljali za vse vrste gradenj in ne samo za industrijske ter inženirske objekte. Beton in druge tehnološke prednosti so-

3 Pripravljali so ga iz vode, peska, apna, pucolana in zdrobljene opeke. Z razvojem graditeljstva so izoblikovali tehnologijo vlivanja mase v leseni opaž in dosegali lastnosti betona, ki ustrezajo današnjim normativom. Rimljani so tudi do skrajnosti izrabili fizikalne lastnosti tega gradiva in za seboj pustili nekaj vrhunskih primerov, kot so Neronova Zlata palača, Panteon, številni akvedukti ipd. Beton pa je krhek material, ki ima visoko tlačno in nizko natezno trdnost. $\mathrm{Z}$ namenom ojačitve in izboljšanja karakteristik mu dodajamo armaturo $\mathrm{v}$ obliki palic ali mreže. Armatura namreč poveča natezno trdnost materiala.

4 Sodobne betonske mešanice sestavljajo cement, agregat in voda ter kemijski in mineralni dodatki. 
dobnega gradbeništva so izrabljali za ustvarjanje novih arhitekturnih form, kot so na primer skeletna gradnja, obešene fasade in ekstremne lupinaste konstrukcije (Bernik, 1992, 42).
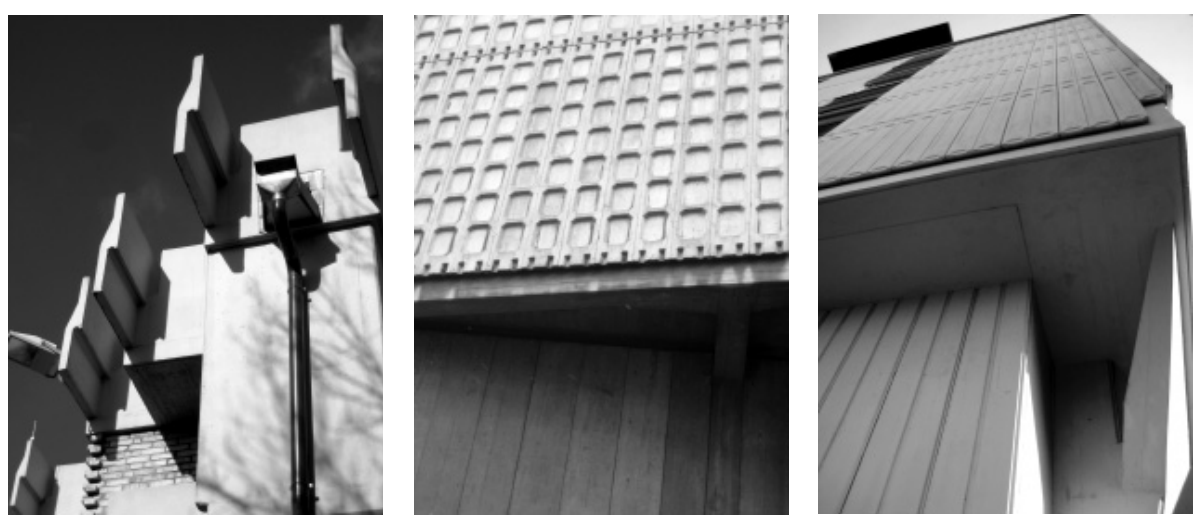

slika 3: Primeri avtorske obdelave vidnega betona. Edvard Ravnikar, Banka v Kranju, Fakulteta za gradbeništvo in geodezijo v Ljubljani, hotel Creina v Kranju foto: T. Potočnik

Beton, prej znan le kot konstrukcijski material, se je v okviru moderne arhitekture pojavil tudi v vlogi vidnega estetskega parametra, kot t. i. vidni beton. ${ }^{5}$ Vidni beton je beton, ki je namenoma razkrit in obdelan $z$ bogatimi teksturami in vzorci (Macdonald, 1997, 211). Avtorsko oblikovani vidni beton, ki učinkuje s svojo teksturo, barvitostjo in konstruktivno izraznostjo, je tako ena pomembnih značilnosti moderne arhitekture.

Moderna arhitektura je sestavni del slovenske kulturne dediščine in zato izrednega pomena. Kljub temu so številni objekti v zelo slabem stanju ali pa so bili celo porušeni. Tako se postavlja vprašanje, kako je pri nas urejena zaščita stavbne dediščine obravnavanega obdobja ter ali je ta zaščita zadostna. Kritično stanje moderne arhitekture je tudi posledica problemov, ki so specifični in izhajajo iz njenih osnovnih lastnosti. Kakšna je torej konservatorska problematika prenove moderne arhitekture?

5 Beton se je kot vidni beton začel uporabljati šele v drugi polovici dvajsetega stoletja. Poskusi so se pojavljali že v prvi polovici stoletja, le da so bile to večinoma industrijske ali utilitarne stavbe, ki so bile »nepokrite« iz ekonomičnih razlogov. Šele Le Corbusier je ustvaril resnično prepoznavno estetiko betona s stavbami Unite d'Habitation. 


\section{Zaščita moderne arhitekture v Republiki Sloveniji}

Temelj konservatorske dejavnosti v svetu na področju arhitekturne dediščine modernizma so organizacije (kot sta $\mathrm{ICOMOS}^{6}$ in $\mathrm{DOCOMOMO}^{7}$ ), ki se ukvarjajo $\mathrm{z}$ varovanjem, obnavljanjem in drugimi dejavnostmi ohranjanja te kulturne dediščine, ter različni statuti, med njimi zlasti Priporočilo št. R (91) $13 .{ }^{8} \mathrm{~V}$ Sloveniji dejavnost ohranjanja stavbne dediščine in s tem tudi moderne arhitekture temelji na delu Zavoda za varstvo kulturne dediščine Slovenije ter delovne skupine DOCOMOMO Slovenija, zakonski okvir pa je postavljen $\mathrm{z}$ Zakonom o varstvu kulturne dediščine in vpisom $\mathrm{v}$ Register kulturne dediščine.

Zakon o varstvu kulturne dediščine (ZVKD-1), ki je bil sprejet februarja 2008, določa načine, pristojnosti ter obseg dejavnosti v okviru ohranjanja dediščine. Zavzema se za celostno varovanje in zagotavljanje nadaljnjega obstoja ter obogatitve dediščine, njenega vzdrževanja, obnove, uporabe in oživljanja. Pri tem so najpomembnejši instrument varovanja varstveni režimi, ki določajo merila za posege. Posegi in spremembe morajo biti izvedeni tako, da čim manj prizadenejo tiste značilnosti objekta, zaradi katerih je bil razglašen za spomenik. Zakon tudi zahteva, da se, preden stečejo postopki varovanja, opravijo raziskave in sestavi konservatorski načrt. To je elaborat, s katerim se določijo sestavine spomenika, ki jih je treba ohraniti, in ki podaja načrt izvedbe del. Za vse posege je treba predhodno pridobiti kulturnovarstvene pogoje in na njihovi podlagi kulturnovarstveno soglasje. Ob tem je nedovoljen vsak poseg $\mathrm{v}$ dediščino, ki se izvaja brez kulturnovarstvenega soglasja ali v nasprotju z njim (Zakon o varstvu kulturne dediščine, 2008, 28.-31. člen).

6 ICOMOS, s polnim imenom The International Council on Monuments and Sites, je organizacija, ki deluje na področju varovanja in ohranjanja kulturne dediščine in ima sedež $\mathrm{v}$ Parizu. Njena uradna spletna stran je http://www.international.icomos.org/.

7 DOCOMOMO International je neprofitna organizacija, ki se ukvarja $\mathrm{z}$ dokumentiranjem in varovanjem arhitekture modernega gibanja. Njeno polno ime je Documentation and Conservation of Modern Movement, uradna spletna stran pa http://www.docomomo.com/.

8 Priporočilo št. R (91) 13 je priporočilo o varstvu arhitekturne dediščine dvajsetega stoletja, ki ga je leta 1991 sprejel Odbor ministrov sveta Evrope. Navaja osnovna načela za načrtno inventarizacijo, merila za izbor, ukrepe za normativno in fizično zavarovanje, upravljanje, razvijanje javne zavesti ter mednarodno sodelovanje. 
Organizacija, pristojna za varstvo stavbne dediščine in s tem tudi moderne arhitekture, je Zavod za varstvo kulturne dediščine Slovenije (ZVKDS). Zavod, ki spada pod Ministrstvo RS za kulturo (Uprava RS za kulturno dediščino), je osrednji javni zavod, ki s svojimi organizacijskimi enotami pokriva celotno območje Slovenije. V okviru javne službe izvaja naloge, ki omogočajo celostno varovanje nepremične kulturne dediščine (Ministrstvo RS za kulturo - področja delovanja, ${ }^{9}$ junij 2009). Temeljna področja delovanja zavoda so ohranjanje, varstvo in zaščita spomenikov ter razvijanje zavesti o dediščini, njenem pomenu in nalogah varstva, še zlasti pri lastnikih in najširšem krogu javnosti. ${ }^{10}$ Poleg tega so naloge, ki jih zavod kot strokovna služba opravlja, predvsem vodenje konservatorskih projektov, zagotavljanje kakovosti konservatorskih dejanj, nadzor, analiza rezultatov, oblikovanje standardov ter stalno upravljanje spomeniških objektov in območij. Ob tem sta ključni vlogi zavoda tudi razvijanje politike in strategije varstva ter določanje varstvenih zahtev (Katalog informacij javnega značaja ZVKDS, ${ }^{11}$ maj 2009.

Stavbna dediščina je zaščitena tudi $\mathrm{z}$ vpisom $\mathrm{v}$ Register kulturne dediščine (RKD). RKD je uradna, računalniško podprta zbirka podatkov kulturne dediščine na območju Republike Slovenije. RKD vodi INDOK center na ministrstvu za kulturo (RKD, ${ }^{12}$ junij 2009). Vsaka vpisana enota dediščine ima svojo evidenčno številko (EŠD). Vpis v RKD zajema identifikacijo, opis, varstveni režim, lokacijo in povezavo $\mathrm{z}$ drugimi enotami. Na podlagi vpisa $\mathrm{v}$ RKD je dediščina pravno varovana v vseh postopkih. ${ }^{13}$

Pomembno vlogo pri zaščiti moderne arhitekture ima, tako kot v svetu, tudi v Sloveniji mednarodna organizacija DOCOMOMO. Ukvarja se z evidenco, valorizacijo, zaščito in prenovo moderne arhitekture. Tudi Slovenija

9 http://www.mk.gov.si/si/delovna_podrocja/kulturna_dediscina/nepremicna_kulturna_dediscina/ <junij 2009>.

$10 \mathrm{~V}$ slovenski spomeniški terminologiji se za opisovanje konservatorske dejavnosti uporablja sledeča doktrina. Najširši pojem je »ohranjanje«, ki ustreza angleškemu izrazu »conservation«. Podrejena pojma sta »varstvo«, ki ustreza angleškemu izrazu "protection«, in »zaščita" oziroma angleško "preservation «.

11 http://www.zvkds.si/media/pages/documents/Kataloginformacijjavnegaznacaja_09.pdf $<$ maj 2009>.

12 http://www.zvkds.si/sl/varstvo-kulturne-dediscine/register-kulturne-dediscine/ <junij 2009>.

13 Spletni iskalnik po registru je dostopen na spletni strani http://rkd.situla.org/. 
je članica mreže DOCOMOMO International in deluje na tem področju z delovno skupino DOCOMOMO Slovenija. Zaradi stanja ogroženosti, v katerem se je znašla moderna arhitektura na Slovenskem, si skupina DOCOMOMO Slovenija prizadeva za vpis slovenske moderne arhitekture v mednarodni register dediščine pri DOCOMOMO International. Na lokalni ravni skupina poskuša dvigniti zavest o pomenu varovanja moderne arhitekture $\mathrm{z}$ informiranjem javnosti, organiziranjem razstav, strokovnih srečanj in ekskurzij, $\mathrm{z}$ izobraževalnim delom na fakultetah ter $\mathrm{z}$ aktivno pomočjo strokovnjakom ZVKDS pri zaščiti te dediščine. Skupina DOCOMOMO Slovenija je zaslužna tudi za organizacijo nekaterih dogodkov, ki so bistveno vplivali na razvoj varstva moderne arhitekture pri nas in povezali najvidnejše domače in tuje strokovnjake s področij varovanja arhitekturne dediščine (DOCOMOMO Slovenija - prenova vidnega betona, ${ }^{14}$ junij 2009).

Kljub zgoraj navedenim dejavnikom zaščite in prizadevnosti nekaterih akterjev, predvsem Društva arhitektov Ljubljana (DAL) in posameznih strokovnjakov, je moderna arhitektura na Slovenskem zelo ogrožena. Še zlasti to velja za stavbe iz šestdesetih let oziroma dela Ljubljanske arhitekturne šole. Društvo arhitektov Ljubljana in Zavod Dessa sta leta $2003 \mathrm{v}$ ljubljanski galeriji Dessa pripravila razstavo »Pozabljene, skažene, porušene«, ki je obravnavala perečo problematiko uničevanja moderne arhitekture na Slovenskem. ${ }^{15} \mathrm{~V}$ zadnjem desetletju so bili namreč porušeni kar trije objekti arhitekta Savina Severja, in sicer paviljon tehničnega centra AMZS in učne delavnice v Ljubljani ter razstaviščni objekt Gorenjskega sejma v Kranju. Podobna usoda je doletela enega najlepših primerov slovenskega regionalizma - hotel Prisank v Kranjski Gori, delo Janeza Lajovca, ki je bil porušen leta $2003 .{ }^{16}$ Prenekateri pomembni objekti pa so bili iznakaženi. Veličastni interier Nove ljubljanske banke arhitekta Edvarda Ravnikarja

14 http://www.trajekt.org/documents/docomomo2006.pdf <junij 2009>.

$15 \mathrm{Z}$ razstavo, ki je bila posvečena arhitekturi povojnega obdobja oziroma Ljubljanski šoli za arhitekturo, sta organizatorja skušala opozoriti na problematiko izginjanja in uničevanja slovenske moderne arhitekture.

16 Eden od močnejših tokov že omenjenega slogovnega pluralizma v okviru slovenske moderne arhitekture je bil tudi regionalizem. Težnje regionalističnega arhitekturnega oblikovanja so nastopile kot izraz posameznih pokrajin in so združevale zavestno uporabo sodobnega arhitekturnega besednjaka $\mathrm{z}$ značilnostmi pokrajine. 
na Trgu republike v Ljubljani je bil popolnoma predelan, prav tako so bili na udaru Ravnikarjev interier stavbe OLO v Kranju, fasada veleblagovnice Nama avtorjev Bogdana Finka in Miloša Lapajneta, hotel Lev avtorja Emila Medveščka in trgovski objekt arhitekta Miloša Bonče v Hrastniku. Ogroženi pa so še številni drugi objekti (Matos, 2003, 54). Evidentno je torej, da moderna arhitektura v Sloveniji ni dovolj zaščitena.

\section{Ohranjanje moderne arhitekture: značilna konservatorska problematika}

Moderna arhitektura je s svojimi oblikovnimi, materialnimi in strukturnimi novostmi v konservatorsko stroko vpeljala številne nove probleme. $\mathrm{V}$ nadaljevanju sledi šest značilnih problemskih sklopov, ki se kažejo v okviru ohranjanja moderne arhitekture.

\section{Problem slabe evidentiranosti moderne arhitekture na Slovenskem}

Pogoj za vzpostavitev varstva in izhodišče konservatorske dejavnosti v okviru obravnavanega stavbnega fonda je temeljita dokumentacijska osnova. Potreba po izčrpnem pregledu z valorizacijo in navedbo stanja je velika tudi zaradi velike količine objektov, nastalih v obdobju po letu 1945 (Prudon, 2008, 156). Prav tako je identificiranje dediščine, njenih vrednot in vrednosti, njeno dokumentiranje, preučevanje in interpretiranje vključeno v zakonu (Zakon o varstvu kulturne dediščine, 2008, 2. člen). Kljub temu je stavbna dediščina modernizma v Sloveniji v primerjavi s starejšo arhitekturno dediščino slabo raziskana in evidentirana. $\mathrm{V}$ preteklosti so se pri nas sicer že pojavljala prizadevanja na področju celostnega evidentiranja stavbne dediščine modernizma. Tovrsten poskus predstavljata sledeči publikaciji. V raziskavi Evidenca in valorizacija slovenske moderne arhitekture med leti 1945 in 1970 avtorji Vojteh Ravnikar, Maruša Zorec, Tina Gregorič in Nataša Koselj obravnavajo 120 arhitektur, nastalih v obdobju modernizma. Ob pomembnejših avtorjih Ljubljanske arhitekturne šole raziskava vključuje nekaj manj znanih avtorjev, ki so s svojimi realizacijami sooblikovali omenjeno obdobje. Bistveno je, da raziskava vključuje tudi stanje 
posamezne arhitekture in izvedene posege ter predlog zaščite. ${ }^{17} \mathrm{Ob}$ tem je pomembna še publikacija ZVKDS iz leta 2001, ki je izšla ob vsakoletnem dogodku Dnevi evropske kulturne dediščine, ki ga pripravlja zavod. Delo iz zbirke DEKD z naslovom 20. stoletje: arhitektura od moderne do sodobne: vodnik po arhitekturi obravnava tipične arhitekture dvajsetega stoletja. Uvodna besedila, katerih avtorji so Jelka Pirkovič, Miha Dešman in Gojko Zupan, opredeljujejo arhitekturo dvajsetega stoletja na Slovenskem, obenem pa prispevajo $\mathrm{k}$ razumevanju konservatorske problematike $\mathrm{v}$ tem okviru. V nadaljevanju sledi izbor arhitektur, ki večinoma vključuje tudi opis stanja in izvedenih del na posameznem objektu oziroma urbanističnem spomeniku. Poleg zgoraj navedenih obširnejših tiskanih objav pomeni bistven prispevek v okviru dokumentiranja moderne arhitekture tudi spletni arhitekturni vodnik, ki je prvi večji pregled slovenske arhitekture in urbanizma 20. stoletja na spletu. ${ }^{18}$ Arhitekturni vodnik podaja osnovne informacije o strokovno zanimivih stavbah, urbanističnih in krajinskih ureditvah ter kulturno-zgodovinskih spomenikih (Trajektov arhitekturni vodnik, ${ }^{19}$ junij 2009). Ključno je, da spletni arhitekturni vodnik poskuša zajeti vse pomembnejše arhitekture obravnavanega obdobja in ne le tiste, ki so že zaščitene kot kulturni spomenik, žal pa ne navaja stanja in predlogov zaščite posameznih arhitekturnih enot. Temeljita evidenca, ki bi imela težo formalnega dokumenta in bi zajemala osnovne podatke o obravnavanem stavbnem fondu, navajala stanje, poškodbe in izvedene posege ter vključevala makete, načrte in druge dokumente, obenem pa predlagala še ustrezno zaščito, ne obstaja.

\section{Problem negativnega vrednotenja}

Vrednotenje je jedro konservatorskih postopkov. Velik problem tako predstavlja negativno vrednotenje arhitekturnih dosežkov modernizma. Ta stavbni fond namreč zavrača tako del laične kot tudi del strokovne javnosti. Med vzroki za negativno vrednotenje oziroma zavračanje prednjači

17 Vsebina dela je v elektronski obliki dostopna tudi na spletni strani http://www.evidenca.org/ evidenca_1945-70.pdf.

18 Arhitekturni vodnik je dostopen na spletni strani http://www.arhitekturni-vodnik.org/.

19 http://www.arhitekturni-vodnik.org/?menu=20 <junij 2009>. 
splošno odklonilen odnos do te arhitekture. Na strani stroke ta nastopa zaradi nepoznavanja oziroma neusposobljenosti za razpoznavanje kvalitet arhitekture tega obdobja. Nepoznavanje moderne arhitekture je posledica slabe raziskanosti problemov gradnje, naročnikov, vloge oblasti, šolanja arhitektov in pomanjkanja celovitega pregleda arhitekturnega ustvarjanja $\mathrm{v}$ obravnavanem obdobju. ${ }^{20} \mathrm{Na}$ strani laične javnosti pa je poleg navedenega prisoten tudi nezadovoljiv odnos do dediščine same. Negativno vrednotenje obravnavanega stavbnega fonda se v praksi kaže tudi tako, da so redka dela še živečih avtorjev, oziroma tista, ki so bila zgrajena po drugi svetovni vojni, razglašena za kulturni spomenik (Pirkovič, 2001, 12). Dodaten problem je dejstvo, da se arhitektura po letu 1945 pogosto povezuje s tedaj vladajočo ideologijo in se jo lahko danes zavrača kot kulturno dediščino že zaradi ideološke obremenjenosti. Arhitektura je namreč pogosto likovno ali vsebinsko simbolna, zato je bila lahko v preteklosti včasih osovražena ne glede na svoje kvalitete. Taka situacija je nastopila ob večjih družbenih spremembah, ob menjavi političnih sistemov in tudi po obeh svetovnih vojnah (Fister, 1979, 11).

S problematiko vrednotenja je povezana tudi »časovna bližina« nastanka moderne arhitekture, ki predstavlja precejšnjo težavo pri tem, da bi jo obravnavali kot kulturno dediščino. Časovni prag, ki je ločeval spomenike od »sodobnosti«, je bil na ravni Avstro-Ogrske, pod katero je tedaj spadalo slovensko ozemlje, postavljen že na začetku prejšnjega stoletja. Leta 1904 je nastal predlog avstrijskega zakona, katerega avtor je bil Alois Riegl in ki je spomenik definiral kot delo, starejše od 60 let. Določitev takega časovnega odmika je nastala ob veliki količini takratne sodobne produkcije, ki naj bi ovirala strokovno izbiranje in dokumentiranje objektov s spomeniško vrednostjo. Danes večina zakonskih ureditev v okviru varstvenih politik v tujini ne določa časovne meje. Izjema sta na primer Portugalska in San Marino, kjer zavarovanje sodobne arhitekture ni mogoče. Tudi v Angliji, kjer je do leta 1988 veljalo upoštevanje časovnega odmika 30 let, so za izjemne

20 Obenem pa je poznavanje tega stavbnega fonda nezadovoljivo tudi zato, ker obravnavanje moderne arhitekture ni vključeno v študijske programe v okviru vseh študijskih smeri, ki bi to tematiko morale vključevati. Skrb vzbujajoče je, da se odklonilen odnos do moderne arhitekture, verjetno zaradi zgoraj navedenih razlogov, pogosto kaže v okviru umetnostnozgodovinske stroke. 
primere časovni odmik že odpravili (Pirkovič, 2001, 12). Pri nas zakon ne določa nikakršne časovne omejitve. Tudi če bi zahteval nekaj desetletij časovne distance, bi danes v spomeniškovarstvene procese lahko vključili večino stvaritev moderne arhitekture. Časovna distanca verjetno res pripomore k objektivnosti vrednotenja. Gotovo je bila določitev nekaj desetletij časovne distance pred sto leti sprejemljiva, toda danes je zaradi hitrejšega tempa sodobnega življenja nerazumna. Tako ostaja odprto vprašanje, kakšna naj bo najmanjša potrebna časovna odmaknjenost, glede na to, da lahko arhitektura propade hitreje, kot je lahko zagotovljena objektivnost vrednotenja.

\section{Problem sanacije materiala}

Eden bistvenih vzrokov za propadanje moderne arhitekture in s tem poglaviten problem konservatorske stroke je povezan $\mathrm{z}$ materialom, iz katerega je moderna arhitektura zgrajena. Prevladujoč material v gradbenih sistemih je kljub slogovni in tipološki raznolikosti moderne arhitekture armirani beton. Od njegovih doseženih lastnosti, vgradnje in vzdrževanja, prav tako pa tudi dejavnikov, ki povzročajo poškodbe, je odvisna trajnost armiranobetonskih objektov. Zato je prenova betona v konservatorski dejavnosti osrednji problem (Macdonald, 1997, 207).

Armiranobetonske konstrukcije so v vsej svoji življenjski dobi izpostavljene morebitnim poškodbam. Glavni vzrok njihovega propadanja je običajno kemijski proces korozije armature, ki je posledica agresije kemijskih snovi iz okolice. Pri korozijskem procesu nastajajo korozijski produkti, za katere je značilno povečanje prostornine, kar privede do pokanja materiala in kasneje luščenja celih plasti (Sanacije betonskih objektov, 2004, 106). $\mathrm{Na}$ armiranobetonske konstrukcije delujejo tudi različni škodljivi fizikalni procesi, ki se sprožijo zaradi mehanskega delovanja okolja in povzročajo obrabo betonskih površin ter razpoke in lome. Armiranobetonski elementi propadajo tudi zaradi mikroorganizmov in vegetacije, ki prodre $\mathrm{v}$ material (Sanacije betonskih objektov, 2004, 88). Poškodovane armiranobetonske objekte je treba sanirati, sanacijski postopki pa obsegajo različne posege $\mathrm{v}$ konstrukcijo. Problem nastopi, ko so ti neustrezni, saj so poškodbe pogosto 
nestrokovno in le površinsko sanirane, korozijska žarišča niso odpravljena in propadanje se nadaljuje.

Resen problem v okviru prenove arhitekture modernega obdobja je tudi sanacija vidnega betona. Podobno kot pri betonskih konstrukcijskih elementih je tudi pri vidnem betonu največja težava korozija. Prenova avtorsko obdelane betonske površine pa je problematična zaradi njene poudarjene izrazne funkcije (Macdonald, 1997, 211). Poškodbe vidnega betona so pogosto sanirane nestrokovno, velikokrat pa je vidni beton tudi prebarvan. Toda kakršnokoli prekrivanje vidnega betona ni sprejemljivo, saj se s tem izgubi osnovna ideja o sporočilnosti in lepoti gradbenih materialov in konstrukcij samih po sebi. Za sanacijo poškodb na površinah, ki s teksturo in vzorci sooblikujejo celoto, je potrebno restavratorsko znanje. Kako prenoviti vidni beton in obenem ohraniti njegovo izraznost, ostaja eno temeljnih vprašanj v okviru konservatorske problematike na področju prenove moderne arhitekture.

Poleg sanacije betona je problematična tudi sanacija »novih" materialov. Za obdobje po drugi svetovni vojni je bil namreč značilen hiter razvoj in širitev spektra gradbenih materialov, ki pred uporabo niso bili vedno dovolj raziskani. Za plastične mase, kovine, barve in druge materiale pogosto še niso bile znane karakteristike in najbolj primerne metode uporabe. Tudi kontrola kvalitete materiala in poteka same vgradnje je lahko bila nezadostna. Danes so ti materiali močno podvrženi propadanju. Včasih je mogoče poškodbe sanirati $\mathrm{z}$ minimalnimi posegi $\mathrm{v}$ material in se s tem izogniti uničenju estetske in materialne avtentičnosti, pogosto pa se je treba odločiti za zamenjavo. Zamenjava poškodovanega elementa lahko zahteva ročno izdelan in drag nadomestek, saj material, ki je bil tedaj uporabljen, pogosto ni več dostopen. Tedaj novo razviti materiali so bili hitro nadomeščeni z drugimi, proizvodnja pa je pogosto obstajala le kratek čas in je bila ob neaktualnosti materiala opuščena (Macdonald, 1997, 211). Ali naj bo tako material, ki je bil del poceni masovne produkcije, ohranjen za vsako ceno? Problem prav tako predstavljajo materiali, ki so okolju škodljivi in so danes opuščeni oziroma prepovedani. Nemogoče jih je namreč nadomestiti z enakim tipom (Prudon, 2008, 178). Ob tem se postavlja še vprašanje ekonomske in idejne upravičenosti nadomeščanja materialov in sistemov 
slabe kakovosti. Veliko težav povzročajo tudi kombinacije materialov v stavbnih sistemih.

Za tradicionalne stavbe iz kamna in lesa so bile v zadnjih sto letih razvite metode, $s$ katerimi je mogoče maksimalno ohraniti material in zasnovo, obenem pa stavbi zagotoviti prihodnost. Zaradi nekaterih karakteristik materialov in parametrov uporabe konservatorske metode še niso dovolj razvite za posege v okviru moderne arhitekture (Macdonald, 1997, 207). Ob vsaki menjavi originalnega materiala, ki gradi spomenik, tako nastopi konflikt s splošnim konservatorskim načelom zagotavljanja avtentičnosti. To v konservatorski stroki pomeni težnjo ohraniti prvotne materiale in originalne koncepte zasnove. Tudi za moderno arhitekturo bi bilo treba poiskati rešitve, ki bi omogočale kompenzacijo »slabih lastnosti« nekaterih elementov. S sistemi, ki bi kompenzirali na primer izgubo energije zaradi originalnih, a danes »energetsko neustreznih« oken, bi bilo možno ohraniti originalen dizajn in avtentičnost materiala.

\section{Problem slabega vzdrževanja}

Kot eden glavnih vzrokov za propadanje moderne arhitekture se kaže nepravilno vzdrževanje. Za mnogo "novih « materialov in posledično tudi za stavbni fond, ki se jih poslužuje, je v preteklosti veljalo zmotno mnenje, da ne potrebujejo veliko vzdrževanja. Tako so tudi za beton mislili, da bo trajal večno. Nasprotno danes vemo, da stavbe 20. stoletja zahtevajo enako stopnjo vzdrževanja kot arhitektura katerega koli zgodnejšega obdobja (Macdonald, 2001, 39). Nepoznavanje zahtev vzdrževanja novih materialov in stavbnih sistemov ter neizvajanje vzdrževanja po danih priporočilih je zaradi brezbrižnosti odgovornih lastnikov ali upravljavcev privedlo do neizogibnega propadanja moderne arhitekture. Ob problemih v zvezi s propadanjem materiala in konstrukcije se kaže tudi slab odnos do celostne zunanje podobe moderne arhitekture, oblikovnih elementov objekta in notranje opreme (Pirkovič, 2001, 21). Uporabniki oziroma lastniki stavbe neprestano prilagajajo svojim vsakdanjim potrebam. Funkcioniranje oziroma uporaba stavbne dediščine je sicer $\mathrm{z}$ varstvenega vidika zaželena. Toda prilagoditveni posegi, ki niso strokovno izvedeni, lahko stavbi zelo škodujejo (Knidred, 1996, 29). Zlasti je pereče samovoljno zastekljevanje ali zapiranje 
balkonov, menjava okenskih okvirjev in namestitev klimatskih naprav, ki popolnoma degradirajo fasade. Pogosto je popolnoma uničena ali zamenjana notranja oprema.

Zdi se tudi, da večji del moderne arhitekture ob staranju ne dosega posebne očarljivosti, kot naj bi bilo to značilno za arhitekturo zgodnejših obdobij. Vsaka sprememba je razumljena kot pomanjkljivost, ki jo je treba čim prej odpraviti. Zato se izvršujejo številna »lepotna« popravila, kot na primer barvanje, zamenjava elementov in čiščenje površin, ki pa zopet potekajo brez strokovnega nadzora (Pirkovič, 2001, 21).

Vsakršno samovoljno poseganje $\mathrm{v}$ arhitekturo postavlja pod vprašanje osnovna konservatorska načela, kot so minimalna intervencija, maksimalna ohranitev originalnega materiala, ohranitev stanja (conserve as found) ter reverzibilnost in ohranitev avtentičnosti. Poleg tega moderna arhitektura funkcionira kot celota, zato je, tako kot stavbno telo, treba varovati tudi notranje ureditve in vse pripadajoče elemente.

\section{Problem nefunkcionalnosti}

Moderna arhitektura je, podobno kot stavbna dediščina zgodnejših obdobij, izpostavljena največji škodi, kadar je zapuščena ali kadar v njej poteka neustrezna dejavnost. Splošni varstveni režim za spomenike sicer opredeljuje varovanje originalne namembnosti, dovoljuje pa novo funkcijo, če ta ekonomsko upravičuje prenovo in hkrati upošteva načelo zvestobe arhitektonskemu in zgodovinskemu značaju stavbe. Kljub temu zahteva vzpostavitev prvotnega stanja, če to omogoča kontinuirano rabo objekta (Kulturna dediščina - varstveni režimi, ${ }^{21}$ junij 2009). Novo uporabo stavbne dediščine je tako treba pravilno določiti in jo poiskati najprej v enaki ali sorodni namembnosti arhitekture. Če to ni izvedljivo, je treba poiskati tako uporabo, ki jo stavba prenese. Prilagoditev stavb za novo namembnost je problematična zaradi več razlogov. Na prvem mestu je manjša prilagodljivost moderne arhitekture v primerjavi s tradicionalno arhitekturo za nove vsebine. Za stavbni fond modernega gibanja je namreč zaradi splošne

21 http://www.zvkds.si/sl/nasveti-za-lastnike/kulturna-dediscina/ <junij 2009>. 
težnje po največji funkcionalnosti in zaradi specializacije prostorov značilna manjša fleksibilnost. Problem pri dodelitvi novih vsebin pa je lahko tudi sama velikost struktur. Tipičen primer, kjer nastopijo problemi pri določanju nove namembnosti, so bolnišnice, vojašnice, utilitarni objekti in zlasti industrijska arhitektura (Pirkovič, 2001, 20). Zahteva po novi funkcionalnosti stavbe se lahko pokaže tudi zaradi potrebe po prilagoditvi novim prostorskim in načrtovalnim zahtevam. Včasih je tako treba zaradi sodobnih okoljskih zahtev (na primer porabe energije) ali zdravstvenih in varnostnih zahtev izvesti določene spremembe (Macdonald, 1997, 208). Splošni varstveni režim za spomenike take spremembe zaradi prilagoditve novim predpisom, novim tehničnim, požarnim in drugim standardom, dostopnosti za invalide in podobno tudi dopušča. Arhitektura je namreč živ organizem in jo je treba prilagajati sodobnemu življenju, novi uporabi, zahtevam in pričakovanjem. V zvezi s tem pa se v praksi pojavlja problem prilagajanja zakonsko določenim gradbenim predpisom. Zakon o graditvi objektov (ZGO-1) obravnava spreminjanje tehničnih značilnosti obstoječega objekta in prilagajanje objekta spremenjeni namembnosti ali potrebam ter dela, s katerimi se bistveno ne spremenijo velikost, zunanji videz in namembnost objekta, spreminjajo pa se njegovi konstrukcijski elementi in zmogljivost ter izvedejo druge izboljšave. Gradbeni predpisi določajo tehnične značilnosti objektov. Ti morajo glede na svoj namen izpolnjevati eno, več ali vse zahteve, vezane na mehansko odpornost in stabilnost, varnost pred požarom, higiensko in zdravstveno zaščito ter zaščito okolice, varnost pri uporabi, zaščito pred hrupom, varčevanje $\mathrm{z}$ energijo ter ohranjanje toplote. Pri rekonstrukcijah objektov v javni rabi, ki so zavarovani v skladu s predpisi o kulturni dediščini, zakon sicer dopušča razlikovanje doseženih bistvenih zahtev objekta od predpisanih, vendar samo pod pogojem, da odstopanje ni takšno, da bi bila zaradi njega ogrožena varnost objekta, življenje in zdravje ljudi, promet, sosednji objekti ali okolje (Zakon o graditvi objektov; ZGO-1-UPB1, 2004, 2., 9., 17. člen). Vprašanje pa je, glede na raznovrstnost problemov v praksi, ali bi morda predpisi morali dopuščati večjo fleksibilnost glede prilagajanja gradbenim standardom. 
Problem navzkrižnih interesov spomeniškovarstvene službe, avtorja, investitorja in arhitektov

Pri varovanju moderne arhitekture se pojavlja vprašanje o sami potrebi po varstvu. Ta dvom nastopi v primeru, ko je avtor arhitekture še živ, saj stvaritve še živečih arhitektov varuje že avtorsko pravo. Pri tem se kot avtorsko delo štejejo arhitekturna dela, izvedeni projekti s področja urbanizma ter krajinske arhitekture, prav tako pa tudi skice in načrti. Avtorske pravice pri nas veljajo še sedemdeset let po avtorjevi smrti, uveljavljajo pa jih njegovi dediči. Če je avtorjev več, se rok trajanja avtorske pravice računa od smrti zadnjega soavtorja (Zakon o avtorskih in sorodnih pravicah; ZASP-UPB3, 2007, 5., 59., 60. člen). Težava nastane tudi ob podanem soglasju samega avtorja, ki lahko, zlasti če je povabljen k sodelovanju, dovoli bistvene spremembe svojega avtorskega dela. V Sloveniji je znanih več primerov, ko so avtorji soglašali s spremembo ali celo odstranitvijo svojega dela. ${ }^{22} \mathrm{~V}$ takem primeru lahko nastopijo nasprotja med spomeniškovarstveno ustanovo ter avtorjem ali dediči njegovih avtorskih pravic.

Konfliktno je pogosto tudi razmerje med konservatorsko dejavnostjo in sodobno arhitekturo. Spor izvira zlasti iz različnega pogleda na arhitekturo in prostor. Konservatorji naj bi praviloma težili k ohranjanju vrednot, zaradi katerih je bil določen objekt razglašen za spomenik, kar v največji meri. Nasprotno arhitekti stremijo k ustvarjanju novih elementov in optimalni prilagoditvi spomenika potrebam sodobnega načina življenja. Najbolje bi bilo, da bi arhitekt že obstoječemu kvalitetno oblikovanemu prostoru ustvaril enakovredno dopolnitev, ki ne bi niti razvrednotila prvotne zasnove niti se ji ne bi slepo podredila (Fister, 1979, 13). V tem času poteka prenova Ravnikarjeve Moderne galerije v Ljubljani in veleblagovnice Globus v Kranju ter končno tudi stavbe Kozolec v Ljubljani arhitekta Eda Mihevca. Po končani prenovi bo razvidno, ali je to izvedljivo, saj je vedno prisoten tudi interes lastnika, upravljavca ali investitorja, ki mu lahko arhitektura pomeni zgolj materialno dobrino. Želja po uveljavljanju materialne pravice je prepogosto $\mathrm{v}$ neskladju $\mathrm{z}$ interesi spomeniškovarstvene službe. Namenjanje nezadostnih finančnih sredstev s strani lastnika oziroma investitorja

22 Med njimi je znan zlasti primer Marka Zupančiča, ki je leta 1991 dopustil rušenje svojega Kluba poslancev. 
za ohranjanje ali prenovo arhitekture privede do pritiskov na arhitekte, ki pripravljajo projekt prenove.

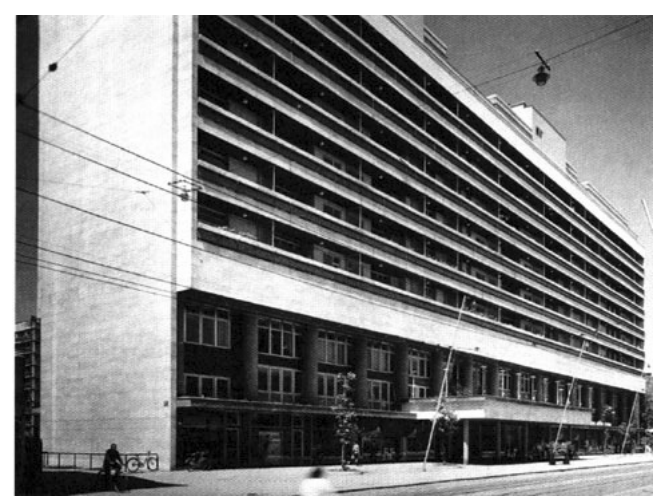

slika 4: Edo Mihevc, Poslovno stanovanjska stavba Kozolec, Ljubljana, 1953, prvoten izgled vir: http://www.arhitekturni-vodnik.org

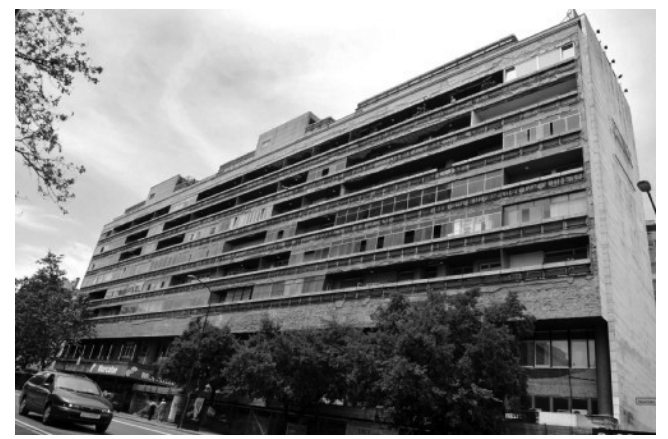

slika 5: Stanje Kozolca pred začetkom prenove vir: http://www.zurnal24.si/export/sites/z24/_data/images/slovenija/kozolec_dmj_ lju_250609.jpg_1263901871.jpg

Takšna situacija je navsezadnje tudi posledica nepovezanosti strok in nepovezanega šolanja za poklice v konservatorski stroki. Očitno je, da je študijska smer, ki bi bila osredotočena na konservatorsko dejavnost in bi združevala znanja s področja arhitekture in projektiranja, gradbeništva, umetnostne zgodovine, ekonomije, prava ter še nekaterih strok, nujno potrebna za ohranitev moderne arhitekture v Sloveniji. 


\section{Zaključek}

Nezadržno propadanje moderne arhitekture odpira v konservatorski stroki vrsto vprašanj, dve pomembnejši pa sta, kako je urejena zaščita $v$ Republiki Sloveniji in kateri specifični problemi nastopajo ob prenovi tega stavbnega fonda.

Moderna arhitektura v Republiki Sloveniji je zaščitena z Zakonom o varstvu kulturne dediščine iz leta 2008 ter z vpisom v Register kulturne dediščine. Pristojna ustanova, ki skrbi za zaščito in konservatorsko dejavnost, je Zavod za varstvo kulturne dediščine Slovenije. Na področju zaščite in ohranjanja pa ima pomembno vlogo tudi organizacija DOCOMOMO Slovenija, ki se osredotoča na moderno arhitekturo in deluje v mednarodnem okviru. Evidentno pa je, da moderna arhitektura kljub vsemu ni dovolj zaščitena, kar potrjujejo številne neprimerne predelave in celo rušitve v zadnjem desetletju.

Specifična konservatorska problematika ohranjanja moderne arhitekture se je oblikovala zlasti v okviru njenih osnovnih karakteristik. Značilne socialne in oblikovne težnje ter uporaba novih konstrukcijskih zasnov in materialov so privedli do sledečih problemov. Moderna arhitektura ni dovolj raziskana in evidentirana. Pogosto je negativno vrednotena in je zaradi tega, ali zgolj zaradi neznanja, neustrezno vzdrževana. Kot eden glavnih problemov se kaže prenova avtorsko oblikovanega vidnega betona in tedaj novih materialov, ki so podvrženi hitremu in "neplemenitemu « staranju. Pereč problem je tudi nefunkcionalnost arhitektur, hitro in učinkovito rešitev pa pogosto preprečujejo navzkrižni interesi spomeniškovarstvene službe, avtorja, investitorja in arhitekta oziroma projektanta.

Ključnega pomena za vzpostavitev in ohranitev optimalnega stanja moderne arhitekture v Sloveniji je povezovanje pri nas sicer nepovezanih področij ter vzpostavitev boljšega pretoka informacij v okviru strok, vključenih v prenovo. Kljub kritičnemu stanju in široki konservatorski problematiki pri prenovi stavbnega fonda moderne arhitekture si lahko pri ohranjanju tega dela naše kulture obetamo boljše rezultate, seveda ob interdisciplinarnem sodelovanju, večjem posluhu za drugačnost moderne arhitekture ter zadostni meri odgovornosti do naše dediščine. 


\section{LITERATURA}

Bernik, S., Pogledi na novejšo slovensko arhitekturo in oblikovanje, Ljubljana 1992.

Bernik, S., Slovenski arhitekturni in oblikovalski modernizmi, v: Umetnost na Slovenskem - od prazgodovine do danes (ur. Golob, N.), Ljubljana 1998, str. 293-329.

Dešman, M., Danes je sin od včeraj in oče od jutri, v: 20. stoletje: arhitektura od moderne do sodobne: vodnik po arhitekturi, Zavod za varstvo kulturne dediščine Slovenije, zbirka Dnevi evropske kulturne dediščine, Ljubljana 2001, str. 24-35.

Dolenc Šoba, M., Šolanje slovenskih oblikovalcev in Ravnikarjeva »B smer«, v: Zbornik za umetnostno zgodovino, nova vrsta XLIII, Ljubljana 2007, str. 266-285.

Fister, P., Obnova in varstvo arhitekturne dediščine, Ljubljana 1979.

Hommage à Edvard Ravnikar: 1907-1993 (ur. Ivanšek, F.), Ljubljana 1995.

Knidred, B., Management issues and Willis Corron, v: Principles and practice in conserving recent architecture (ur. Macdonald, S.), Shaftesbury 1996, str. 29-37.

Koselj, N., Arhitektura 60-ih let v Sloveniji: kontinuiteta ideje, v: $A B$, letnik XXV, november 1995.

Macdonald S., Conserving »carbuncles«. Dilemas of conservation in practice: an overview of current English Heritage research and advice, v: Structure and style. Conserving 20th century Buildings (ur. Stratton, M.), London 1997, str. 207-224.

Macdonald, S., Defining an approach: a methodology for the repair of postwar buildings, v: Preserving post-war heritage. The care and conservation of mid-twentieth-century architecture (ur. Macdonald, S.), Shaftesbury 2001, str. 32-40.

Matos, U., Uničevanje dediščine, Mladina, 28. julij 2003, str. 54-56.

Mehta, P. K., Monteiro, P. J. M., Concrete: microstructure, properties, and materials, New York 2006, str. 3-198. 
Pirkovič, J., Ohranjanje stavbne dediščine dvajsetega stoletja, v: 20. stoletje: arhitektura od moderne do sodobne: vodnik po arhitekturi, Zavod za varstvo kulturne dediščine Slovenije, zbirka Dnevi evropske kulturne dediščine, Ljubljana 2001, str. 11-22.

Ravnikar, V. in drugi, Evidenca in valorizacija objektov slovenske moderne arhitekture med leti 1945-70, aplikativna raziskava, Ljubljana 2000.

Sanacije betonskih objektov (ur. Grum, B.), Ljubljana 2004.

Umetnost: svetovna zgodovina, Ljubljana 2000, str. 610-615.

Uradni list RS, št. 16/2007: Zakon o avtorskih in sorodnih pravicah, uradno prečiščeno besedilo (ZASP-UPB3).

Uradni list RS, št. 102/2004: Zakon o graditvi objektov, uradno prečiščeno besedilo (ZGO-1-UPB1).

Uradni list RS, št. 16/2008: Zakon o varstvu kulturne dediščine (ZVKD-1).

Zupan, G., Arhitektura dvajsetega stoletja, v: 20. stoletje: arhitektura od moderne do sodobne: vodnik po arhitekturi, Zavod za varstvo kulturne dediščine Slovenije, zbirka Dnevi evropske kulturne dediščine, Ljubljana 2001, str. 5-10.

\section{ELEKTRONSKI VIRI:}

http://www.arhitekturni-vodnik.org/

http://www.docomomo.com/

http://www.evidenca.org/

http://www.icomos.org/

http://www.mk.gov.si/

http://www.trajekt.org/

http://www.uradni-list.si/

http://www.zvkds.si/

http://rkd.situla.org/. 


\title{
MODERN ARCHITECTURE: PROBLEMS OF PROTECTION AND PRESERVATION
}

\author{
Keywords: modern architecture, Ljubljana architectural school, archi- \\ tectural heritage, conservation of modern architecture, le- \\ gal protection of heritage
}

\begin{abstract}
Certain buildings that were part of Slovenian modern architecture built after the Second World War and before the prevalence of postmodernism represent one of the greatest achievements of Slovenian architectural planning. Several architects that were part of the Ljubljana architectural school reached the pinnacle of their creativeness in the 1960s. Although the majority of the edifices that were built are no more than half a century old, they are mostly in very poor condition; some of the buildings have even been demolished. The relentless dilapidation of modern architecture in Slovenia raises many questions concerning the conservation of these buildings. The two crucial questions are how the protection of these buildings is regulated in Slovenia and which specific problems occur during the conservation process.

The legal protection of modern architecture in Slovenia is based on legislation (the Cultural Heritage Protection Act, ZVKD-1), which came into force in 2008, and on an entry in the Register of Cultural Heritage. Two institutions play an important role in conservation: the Institute for the Protection of Cultural Heritage of Slovenia, which is responsible for preserving and protecting cultural heritage in general, and DOCOMOMO Slovenija, an organization that focuses on the architectural heritage of the modern movement and acts on an international basis.

The specific problems concerning the conservation of modern architecture derive from the characteristics of the buildings, social and formal tendencies, and the use of new materials and construction techniques. Modern architecture in Slovenia has not been sufficiently studied and recorded. It was often negatively evaluated and therefore inappropriately maintained.
\end{abstract}


One of the essential problems is the renovation of concrete and "new" materials that rapidly degrade in an inconvenient way. Another problem is that nowadays modern architecture is often non-functional. All of these problems are difficult to solve because of the conflicting interests between the responsible institution, designer, contractor, architect, and so on.

The critical condition of the majority of modern buildings and the wide range of problems concerning conservation of modern architecture in Slovenia indicate that a better understanding of the uniqueness of modern architecture and taking greater responsibility for Slovenian architectural heritage in general is necessary for optimal conservation. 